\title{
Tumor risk assessment by means of immunocytochemical detection of early pre-malignant changes in buccal smears
}

\author{
MARC M. BLOCHING ${ }^{1}$, HANNAH SOULSBY ${ }^{2}$, ANDREAS NAUMANN ${ }^{1}$, WOLFRAM AUST ${ }^{1}$, \\ DANIEL MERKEL ${ }^{1}$, THERESA BRAUN ${ }^{1}$ and RAMIN NAIM ${ }^{1}$ \\ ${ }^{1}$ Department of Otolaryngology, Head and Neck Surgery, University of Saarland, Homburg/Saar, D-66421 Homburg, \\ Germany; ${ }^{2}$ Warwick Medical School, University of Warwick, Coventry, CV4 7AL, UK
}

Received August 23, 2007; Accepted December 21, 2007

\begin{abstract}
Increasing incidence of carcinomas in the upper aero-digestive tract, both in Germany and in other European countries requires development of new preventive strategies. The cure rate at advanced tumor stages remains poor in spite of a variety of available therapeutic methods. In the present study the quantitative assessment of a pre-malignant mucosa lesion within a field cancerization was performed by means of immunocytochemical methods. This may allow individuals with an increased risk of developing malignant disease to be identified. Cytosmears taken from healthy buccal mucosa of tumor patients $(n=50)$ and from healthy probands $(n=100)$ with different tobacco and alcohol consumption levels were examined with regard to identifying increased expression of the proliferation markers (PCNA, MIB1), of the tumor suppressor gene product p53 as well as the oncogene product cyclin D1. There was a significant difference in expression of investigated proliferation markers between tumor patients and healthy probands $(\mathrm{p}<0.0001)$. When comparing the rate of positively marked cell nuclei to cigarette pack years the marker cyclin D1 and MIB1 show an increased rate in the groups with high tobacco consumption as compared to the group with a low exposure $(p>0.05)$. It could be possible to use the marker MIB1 and cyclin D1 to screen risk groups, since the relative morbidity risk (odds ratio) increases (by 45-62 times) if the threshold value of 4 positively marked cell nuclei is exceeded.
\end{abstract}

\section{Introduction}

Since the mid 70s there has been a rise in the incidence and mortality rate of tumors of the upper aero-digestive tract (UADT) in Europe and USA $(1,2)$. Especially with regard to buccal cavity cancers, Germany (factor 3.8) together with

Correspondence to: Dr Ramin Naim, Department of Otolaryngology, Head and Neck Surgery, University of Saarland, Homburg/ Saar, D-66421 Homburg, Germany

E-mail: ramin.naim@gmail.com

Key words: risk assessment, buccal smears, malignant, tumor, field cancerization, prevention, head-neck squamous cell carcinoma
Hungary (factor 3.9) showed the highest increase in mortality in Europe from 1955 to 1992 (3).

Therefore, the German Society of ENT, Head and Neck Surgery recommend secondary prevention, i.e. early cancer diagnosis for high-risk groups (4). However, in spite of these instructions only a small number of preventive measures have been implemented so far (5). This is all the more important as early detection of these cancers results in a good chance of lasting cure if combined with function-retaining therapeutic measures.

Considering these facts, the development of a prevention concept is necessary. Relevant and easily obtainable biomarkers (e.g. from the oral cavity), would allow tumor risk to be assessed for individuals in epidemiologically characterized risk groups. A fundamental prerequisite for these considerations has been the phenomenon of field cancerization, first observed by Slaughter et al (6). According to this phenomenon, the mucosa of the UADT is affected premalignantly by chronic exposure to exogenic noxas, made obvious by the development of syn- or metachronic secondary carcinomas. In order to identify individuals with an increased tumor risk damage to the mucous membrane was classified according to the amount of the harmful substance, individual susceptibility and the presence of a 'carcinogenic environment' in the oral cavity. Thus, it was the aim of the present study to identify suitable biomarkers that indicate the extent of the individual damage to the mucous membrane.

Markers indicating damage to the genome should be found, especially to tumor suppressors or proto-oncogenes since, according to the present knowledge, malignant transformations are mainly due to defects in these genes (7). In normal cells the interplay of proto-oncogenes and tumor suppressor genes is balanced. Depending on site and time, they encode and express proteins influencing cell growth and cell division. Therefore the onco- and tumor suppressor genes constitute the genetic basis of the cancer risk influenced by endogenic and exogenic factors. Thus, there is on the one hand the endogenic oncogenously and regulation-dependent susceptibility of the individual to cancer formation and on the other hand the exogenic mutations and promotion-causing carcinogenic noxas of the environment $(8,9)$. In this way cancer becomes part of a multi-stage process of genetic events, the accumulation of which within the cell may lead to its degeneration (10). A study by Renan showed that 


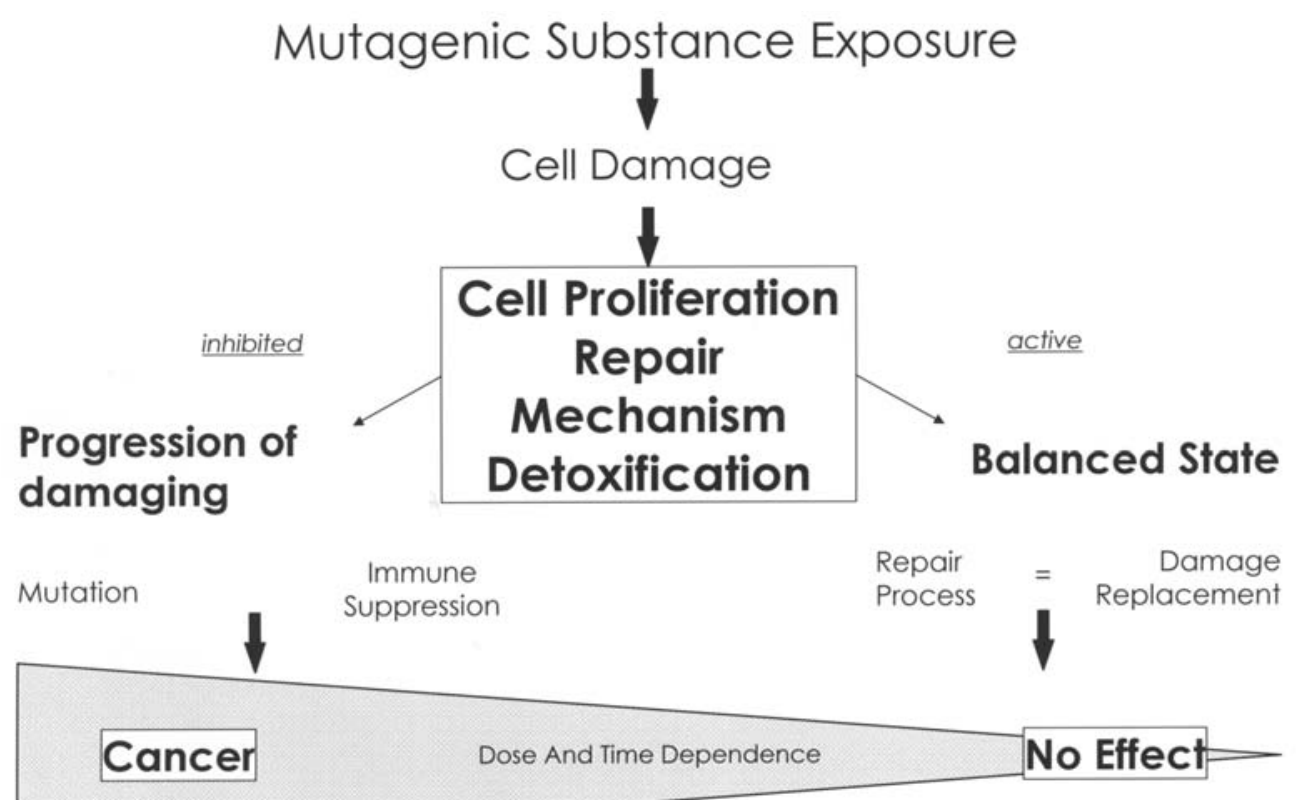

Figure 1. Role of repair- and immune mechanisms in cancer development. Exposure to a mutagenous substance over a long-time period and the damaging and aging of cellular and tissue defence mechanism could disturb the balance between mutation rate and repair mechanisms (32-34).

statistically a malignant cell can be formed through the accumulation of 6-10 different genetic events (12).

Whether DNA is damaged, resulting eventually in malignant transformation and a tumor, essentially depends on the numerous defense and repair mechanisms at the cell and tissue level. Individual susceptibility is determined by, amongst other factors, the efficiency of absorption and metabolic barriers against carcinogenic matter, immune defense and a number of DNA repair mechanisms (Fig. 1).

The object of this study was to examine early morphological and pre-malignant changes. The immunocytochemical proof of an enhanced proliferation or of a disturbed cell cycle control, as reaction to a damaged mucosa, was performed by means of a quantitative demonstration of the proliferation markers Ki-67 and PCNA. An enhanced expression of the p 53 tumor suppressor gene and of the proto-oncogene cyclin D1 in smears taken from the healthy buccal mucous membrane (at least at a distance of $3 \mathrm{~cm}$ from the primary tumor) was also demonstrated.

\section{Materials and methods}

Probands. The study included 150 probands and patients over the period 1998-2002, subdivided into 50 patients with an UADT carcinoma and 100 healthy probands with different tobacco and alcohol consumption levels. Data characterizing the probands are shown in Table I. In order to characterize the group epidemiologically and to assess possible influencial factors each of the participants was interviewed by means of a ques-tionnaire used in cytogenetic population monitoring concerning their age, occupation, habits and state of health (12).

Smear taking. A standardized technique was used to take smears from the buccal mucous membrane, i.e. the mucous
Table I. Proband characteristics.

\begin{tabular}{lcc}
\hline & Patient & Proband \\
\hline No. & 50 & 100 \\
Average age & 57.1 & 53.5 \\
Sex & & \\
$\quad$ Female & 5 & 17 \\
$\quad$ Male & 45 & 83 \\
Smoker & 38 & 60 \\
Non-smoker & 12 & 40 \\
Laryngeal carcinoma & 20 & - \\
Hypopharyngeal carcinoma & 8 & - \\
Oropharyngeal carcinoma & 22 & - \\
\hline
\end{tabular}

membrane was first of all extensively cleared of deposits and devitalized cells by vertical moderate brushing with a multitaft short-bristle toothbrush. A commonly occurring light punctiform hemorrhage indicated that all smears were taken from similar cell layers. By rotating a cervix brush with a slight pressure required cells were obtained (Fig. 2), and transferred, by rolling them off, onto slides. The cells were then checked under the microscope using Papanicolaou staining. The preparations obtained by the above swabbing technique predominantly showed cells from the suprabasal mucous membrane layers.

Staining the slide preparations. Immunocytochemical staining of the preparations (APAAP method) was carried out in the 


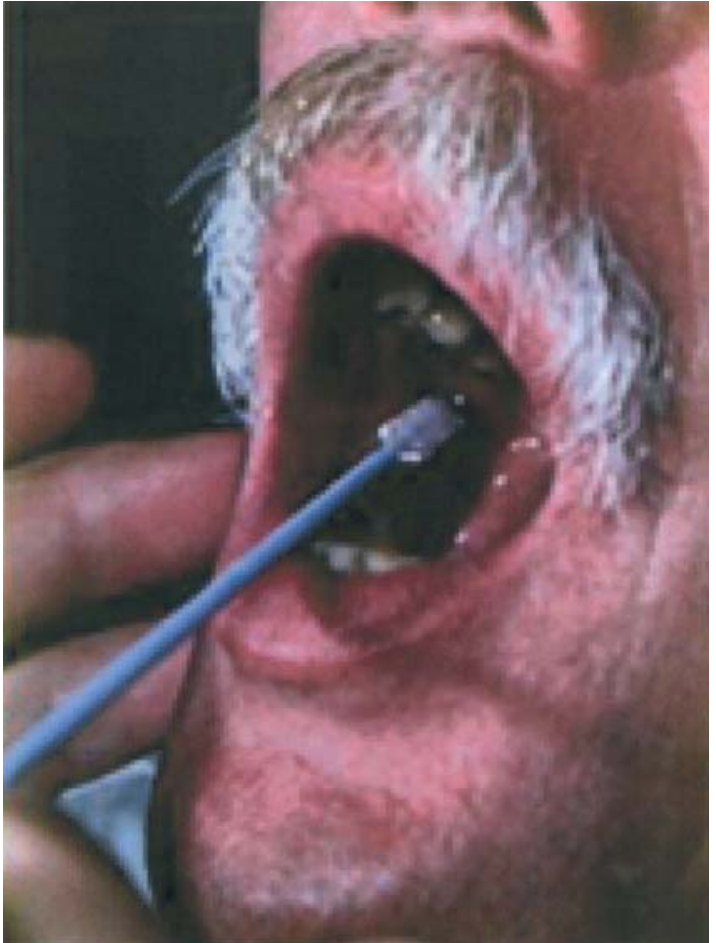

Figure 2. Smear taking from healthy buccal mucosa.

research laboratory of the ENT Department of the MartinLuther University of Halle-Wittenberg according to the following procedure:

Fixation of the microscopic slides in acetone $(10 \mathrm{~min})$ followed by a $10 \mathrm{~min}$ heat treatment at $80^{\circ} \mathrm{C}$ in citrate buffer (10 mM; pH 6.0). The slides were washed between steps with PBS buffer ( $7 \mathrm{mM}$; $\mathrm{pH}$ 7.6). The primary antibody was applied. Concentration and incubation period varied between individuals (see below), the incubation was performed in a wet chamber.
The slides were washed between the individual steps with TBS (0.05 M tribase; $0.15 \mathrm{M} \mathrm{NaCl}$; pH 7.6) (twice $10 \mathrm{~min}$ ). Bridge antibody was applied for $30 \mathrm{~min}$ and the APAAP complex for $30 \mathrm{~min}$

After the last washing, incubation was carried out with the substrate solution, in the wet chamber, for $40 \mathrm{~min}$. The substrate solution was allowed to stand for a maximum of $30 \mathrm{~min}$ before application.

The sample was washed in aqua dest (twice $5 \mathrm{~min}$ ). Slides were counterstained with 1:4 diluted Mayer's hematoxylin then coated with gelatine.

Concentration of the primary antibodies. In order to demonstrate the expression of the antigenes p 53, Ki-67, PCNA and cyclin D1 monoclonal mouse antibodies were used. The necessary concentrations of the individual antibodies was fixed previously in dilution series:

For p53 the monoclonal antibody DO-7 was used against p53 wild-type as well as against mutated forms (Dako, Denmark) (code no. M 7001) in a dilution of 1:25 in PBS standard solution. For PCNA the monoclonal antibody PC 10 was used (Dianova, Hamburg) (art. no. P 56720) in a dilution of 1:250 in TBS buffer. For Ki-67 the monoclonal antibody MIB1 was used (Dianova) (slide 50 5) in a dilution of 1:100 in PBS standard solution and for Cyclin D1 the monoclonal antibody DLS-6 (Calbiochem, Cambridge) (art. no. CC 12) in a solution of 1:20 in TBS buffer.

Positive and negative checkings of each staining phase was performed by means of the cell line UM-SCC11B (provided by T.E. Carey, Ann Arbor, USA).

Evaluation of the preparations. The preparations were evaluated using a light microscope. Distinct red staining of the nuclei was considered to be positive (Fig. 3). Negative nonexpressed cell nuclei stained blue (hematoxylin). The glass slides were systematically observed in a meandering process and evaluated quantitatively, 1000 cells were selected from

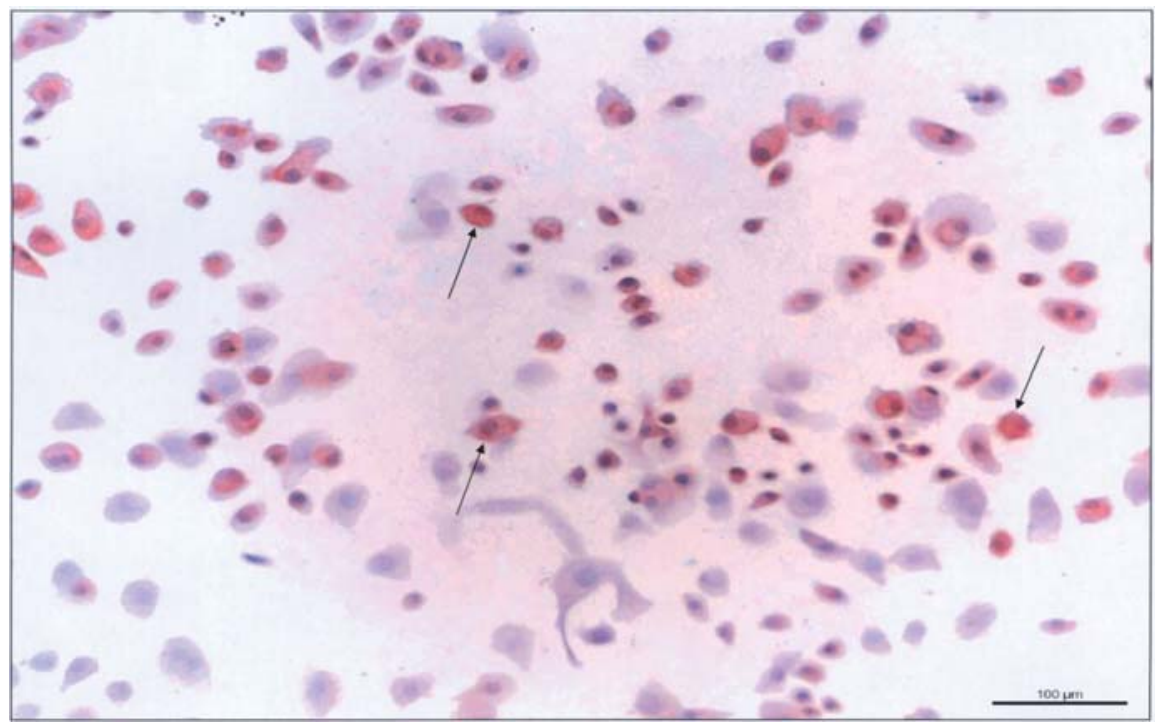

Figure 3. Immunocytochemical presentation of an increased MIB1-expression (red coloured cell nuclei) in a smear of healthy buccal mucosa taken from a tumor patient; magnification, $\mathrm{x} 240$. 
every fourth picture section and checked for positive cells. This procedure provided an optimum and representative survey of the whole slide. Artifacts were shown as atypical forms and colors. Continuous comparisons with a positive control, produced by means of antigen-expressed tumor cells (see above) facilitated differentiation. The following criteria for a positive marking were established: i) intact cell nucleus within a largely intact cell, ii) clear red staining and iii) round and homogeneous nuclear shape.

Statistical methods. Initially participants in this study were stratified into risk groups according to their tobacco and alcohol consumption levels. The rate of the individual markers was determined depending on the case control status as well as on the consumption of tobacco and alcohol. Differences in the expression of the individual markers between cases and controls were examined using the nonparametric $U$ test according to Wilcoxon-Mann-Whitney. The $\chi^{2}$ test was employed to analyze possible differences between cases and controls depending on chosen cut-points. Connections between tobacco and alcohol consumption and the rate of possible cell nuclei were demonstrated with linear regression analysis. In the case of repeated tests corrections were made according to Bonferroni. The relative risk (estimated by odds ratio) of a healthy proband, depending on expressed markers, to suffer from a carcinoma in the UADT was established by logistic regression. Recording of results and evaluation of data was carried out by means of SPSS.

\section{Results}

Descriptive characterization of the participants in the study. Data analysis showed alcohol consumption of 0-513.5 gram per day for all participants (mean value 59.37; standard deviation 89.06). The maximum number of cigarettes per day amounted to 80 (mean value $25.27 ; 15.5$ ). Seventy-six percent of the patients were smokers, $24 \%$ non-smokers. Among the healthy controls $60 \%$ were smokers and $40 \%$ non-smokers. Detailed data on the participants are shown in Table II.

Comparison of the rate of marked cell nuclei in tumor patients and in healthy probands. There was a significant difference in expression of markers between tumor patients and healthy probands in all investigated markers $(\mathrm{p}<0.0001)$ (Fig. 4). A highly-significant difference was also visible in the $\chi^{2}$ test between the rate of the expressed markers in the healthy participants and the patients with a disease taking into account cut-off points $(\mathrm{p}<0.0001)$. Because of the differing expression of the various markers the cut-points of PCNA cyclin D1 and MIB1 were fixed at 4 positively marked nuclei/1000 epithelial cells and in the case of p53 at 3 positively marked nuclei/1000 epithelial cells.

Correlation between the rate of positively marked cell nuclei and tobacco and alcohol consumption. When comparing the rate of positively marked cell nuclei in correlation with cigarette pack years cyclin D1 and MIB1 showed on average an increased tendency of positive cell nuclei in the groups with high tobacco consumption compared to the group with a low exposure $(\mathrm{p}<0.05)$. However, no significant linear

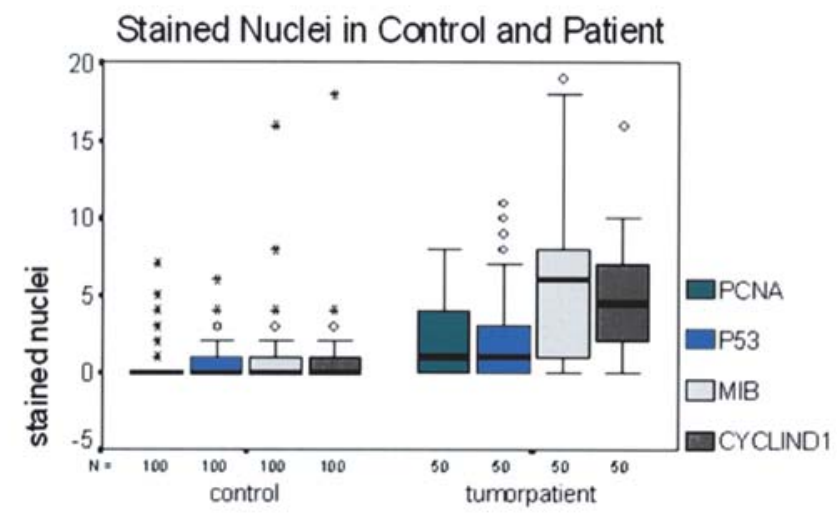

Figure 4. Positive marked cell nuclei depending on the state of the study participants. A statistically significantly raised expression of all investigated markers (especially cyclin D1 and MIB1) in the group of the tumor patients was found.

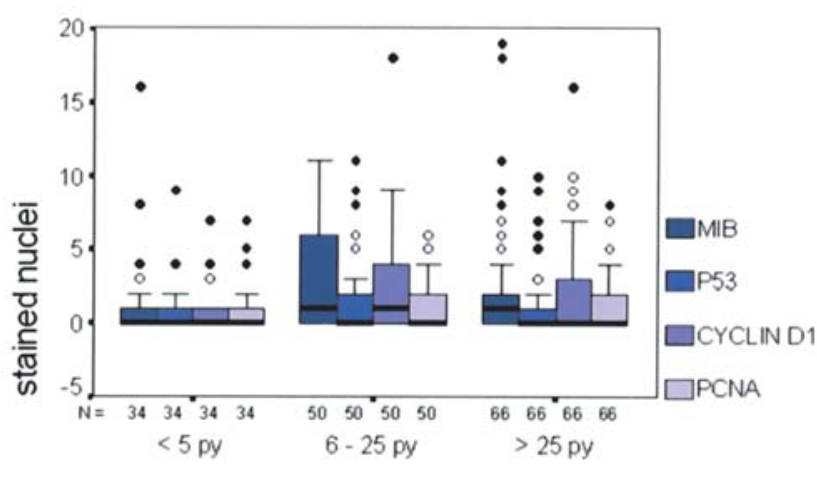

tobacco in pack years

Figure 5. Number of positive marked cell nuclei in correlation to tobacco consumption (measured in pack years).

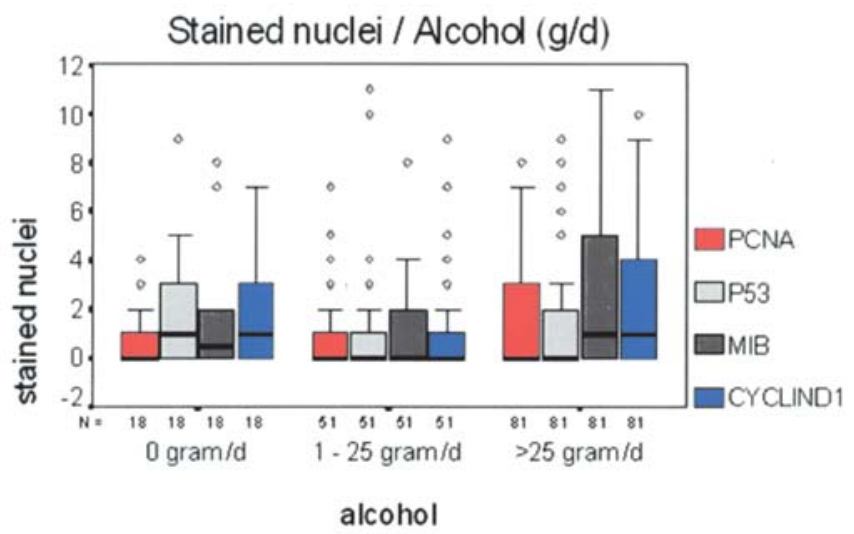

Figure 6. Number of positively marked cell nuclei in correlation to alcohol consumption (measured in g/day).

dependence was revealed between the tobacco consumption measured in the cigarettes consumed per day and packs per year in the rate of positively marked cell nuclei for each measured marker ( $\mathrm{p}<0.05)$, (Fig. 5). A significant correlation 
Table II. Characterization of the participants based on tobacco and alcohol consumption levels.

Tobacco consumption (pack years)

\begin{tabular}{lrrrrr}
$\begin{array}{l}\text { Alcohol } \\
\begin{array}{l}\text { consumption } \\
\text { (g/day) }\end{array}\end{array}$ & $\begin{array}{r}55 \text { pack } \\
\text { years (\%) }\end{array}$ & $\begin{array}{r}5-25 \text { pack } \\
\text { years }(\%)\end{array}$ & $\begin{array}{c}\geq 26 \text { years }(\%) \\
\text { Total }\end{array}$ \\
\hline 0 & $4(11.8)$ & $7(14.0)$ & $7(10.6)$ & $18(12.0)$ \\
$1-25$ & $18(52.9)$ & $15(30.0)$ & $18(27.3)$ & $51(34.0)$ \\
$\geq 25$ & $12(35.3)$ & $28(56.0)$ & $41(62.1)$ & $81(54.0)$ \\
Total & $34(100)$ & 50 & $(100)$ & $66(100)$ & $150(100)$
\end{tabular}

between the amount of alcohol consumed and the number of marked cell nuclei could not be proved to be unconfounded by the consumption of tobacco ( $p>0.05)$, (Fig. 6).

Development of a model for risk assessment using logistic regression. As explained by the preceding results the participants in this study can be assigned with a high degree of probability to either the groups of healthy persons or to that of tumor-afflicted depending on the rate of positively marked cell nuclei. Using multiple logistic regression we investigated which marker combinations are most likely to point to the groups 'healthy' or 'ill'. Introducing cut-points into the model makes the use of the results for future preventive studies easier. The assignment rate of the probands to the groups 'healthy' or 'ill' amounts to $92 \%$ considering all markers. However, the amount of cyclin D1 and MIB1 expressions have the greatest influence $(\mathrm{p} \leq 0.0001)$. Based on these results, a proband has a 62-fold higher risk of suffering from a UADT tumor if the cyclin D1 threshold value of 4 positively marked cell nuclei is exceeded $(p<0.0001)$. When the MIB 1 threshold is exceeded the risk increases by 45 times $(\mathrm{p}<0.0001)$. There is no appreciable interaction of the two markers.

\section{Discussion}

In many cases gradual malignisation of the mucous membrane of the UADT is associated with mutations in defined chromosomal regions. Thus, in the process of gradual tumor progression in dysplasia, carcinomas in situ and invasive carcinomas there is an increasing frequency of a loss of heterozygosity in such locations as $17 \mathrm{p} 13$ (localisation of the p53 gene) and $11 \mathrm{q} 13$ (localisation of the proto-oncogene cyclin D1) (13). These genetic changes may result in an over-expression of the translated proteins p53 and cyclin D1. For this reason we investigated the expression of these proteins (p53 and cyclin D1) in correlation to the introduction of harmful substances and the state of health of the probands using exfoliative cytology.

These considerations coincide with investigations showing a heightened expression of cyclin D1 and p53 in carcinomas of the UADT (14-17). There is also no doubt that heightened or disturbed proliferation (proved by MIB1 and PCNA) often serves as the first sign of tissue damage caused by exogenous noxas. A heightened cell division rate can have an influence on the efficacy of gene-toxic substances, since genetic damage in the initial phase can be fixed more rapidly. On the other hand, epigenetic carcinogenesis can also lead to enhanced proliferation $(18,19)$.

We hope to be able to prove, similar to the analysis of the buccal micronucleus rate in a previous study (20), an increased rate of positively immunocytochemical marked cell nuclei depending on tobacco and alcohol consumption and on the state of health of probands.

MIB1 and PCNA-assessment of the results of the investigations. The results of the present study show an enhanced proliferation of the healthy buccal mucous membrane in tumor patients as compared with healthy probands, measured by means of the markers MIB1 and PCNA. This study is the first to show that an increased proliferation of the buccal mucous membrane can be identified by means of a modified exfoliative cytology. Normally cells of the superficial layers do not express any proliferation markers. This is why we applied our modified technique to remove these superficial cells with a harder brush prior to the final sampling. Several other studies could, however also demonstrate an increased proliferation in a morphologically unchanged mucous membrane using different methods.

Piffko et al detected an increased rate of MIB1 and Ag NOR positive cells at the transition from healthy to hyperplastic and dysplastic mucosa, concluding that the demonstration of these markers could be used to recognize high-risk patients (22). Liu et al obtained similar results when using MIB1, stressing especially the increased expression in the suprabasal region as compared to the basal cell layers in leucoplakias (23). An increase in proliferating cells through PCNA marking was demonstrated by Shin et al, Martinez-Lara et $a l$ and Zain et al also in suprabasal cell layers $(19,24,25)$. These studies concluded that there exists an increased proliferation in dysplastically changed mucous membrane and normal appearing mucosa in tumor patients in the sense of a field cancerization.

Although our study only included probands with nondysplastically altered mucous membrane smears we were able to demonstrate more often immunocytochemically marked cells (MIB1 and PCNA) in the healthy mucous membrane of tumor patients. Thus we can speak of an increased or irregular proliferation in the sense of a field cancerization which can be demonstrated by means of immunocytochemistry even prior to the appearance of classic morphologic changes in the form of dysplastic lesions. Based on these results the proband population shows a 45 -fold increased tumor risk if the MIB1 threshold level of 4 positively marked cell nuclei is exceeded.

p53-assessment of the results of the investigations. Dysregulation of the cell cycle caused by mutations in proto-oncogenes and/or tumor suppressor genes may also point to premalignant damage of the mucous membrane. The exact function of the tumor suppressor gene p53 has not been totally clarified. It probably plays a key role in keeping the genome intact. One of its functions contributes to arresting the cell cyclus in the G1 phase, in order to provide a chance for the cell to repair errors in case of a DNA defect. Normal cells have low concentrations of p53 protein. Its intracellular 
concentration only rises significantly in response to a damaging stimulus (26).

There was a tendency of increasing rate of positively marked cell nuclei against p53 protein in the unchanged mucous mem-brane within the group of tumor patients as compared with the healthy probands.

Considering a threshold value of 3 positively marked nuclei these differences between tumor patients and healthy probands appear to be significant $(\mathrm{p}<0.001)$. Thus an impairment of the buccal mucous membrane can also be confirmed using immunocytochemical means by demonstrating a stronger expression of p53 protein in the buccal mucous membrane epithelial cells in tumor patients in the sense of a field cancerization.

The practical relevance of this is limited as the demonstration of p53 expression in a healthy buccal mucous membrane is poor both in biopsy and in smear cytology. It is, however, an indication of pre-malignant damage of the mucous membrane in tumor patients, so that Bosch et al were hoping to assess a secondary carcinoma risk in tumor patients through the specific demonstration of p53-positive areas (27). To what extent the proved over-expression of the protein actually correlates with mutations in the gene is presently being discussed $(28,29)$.

Cyclin D1-assessment of investigation results. Apart from tumor suppressor genes, proto-oncogene are also targets for mutagenic noxas. Expression products of proto-oncogenes (e.g. cyclin D1) control essential functions such as signal recognition, signal transduction and regulation of proliferation and differentiation. If these genes are activated (by amplification, translocation, mutation) this can also contribute to cell transformation.

The findings of our study show an increase in the number of cyclin D1-positively marked epithelial cells in tumor patients as compared with healthy probands as a sign of field cancerization. This finding is supported by Kyomoto et al and by Bartkova et al who also detected islands with cyclin D1 expressing cells in suprabasal cell layers in morphologically healthy mucous membranes of tumor patients $(30,31)$. Both reports emphasize the importance of an immunochemically demonstrated cyclin D1 expression in the early stages of tumor development.

Risk assessment. Using logistic regression analysis we proved that the relative risk of acquiring a carcinoma in the UADT increases with each further cyclin D1-positive cell nucleus $(\mathrm{p}>0.0001)$. The risk for a proband with more than 4 positively marked cell nuclei of contracting a UADT carcinoma rises by 62.6 -fold. This finding points to the potential importance of demonstrating an expression of cyclin D1 in the healthy buccal mucous membrane as a biomarker for the recognition of high-risk patients.

Conclusion for practice. The regional Health Report of Sachsen-Anhalt (Germany) from the year 2000 shows a particularly high increase in the percentage of teenage female smokers from $27 \%$ in 1993 to $47 \%$ in 1997 . Within the same period of time the percentage of male teenage smokers also rose from 38 to $45 \%$. The majority of smokers in the former
East Germany can be found in the age groups under 20 (men $70 \%$, women $57 \%$ ), whereas the rate of young smokers in the former West Germany is considerably lower. These alarming figures indicate that the incidence of carcinomas of the UADT is going to increase particularly in the former East Germany. Likewise the data stress the need for future preventive measures to reduce lifestyle risk factors such as 'tobacco and alcohol' as well as the importance of early diagnosis strategies.

Immunochemical demonstration of the proliferationassociated markers MIB1 and PCNA as well as of the expression products of the tumor suppressor gene p53 and of the proto-oncogene cyclin D1 in connection with a possible identification of high-risk patients amount to a proper in vitro test. Thus, these investigations contribute to the elucidation of development and progress mechanisms in the cancer process and eventually also to the identification of risk groups in the course of preventive health protection measures. Using biomarkers in UADT appears to be an optimum choice, since, apart from the known risk factors, the phenomenon of field cancerization has to be quantified and preventive measures are possible due to good visual accessibility of the relevant area.

A problematic factor, however, is the small number of demonstrable positively marked cells, especially concerning the markers PCNA and p53, and also MIB1 and cyclin D1. The main reason for this is probably the poor accessibility to the deeper cell layers by means of the commonly used smearing techniques. For practical reasons, markers PCNA and p53 are therefore not suitable for risk group screenings using the quantitative exfoliative immunocytology. Nevertheless they indicate changes in the mucous membrane in tumor patients when compared to healthy probands concerning field cancerization. Using markers MIB1 and cyclin D1 for risk group screenings appears to be possible, since the relative disease risk (odds ratio) clearly increases when the threshold value of 4 positive cells is exceeded.

\section{Acknowledgements}

The study was carried out with the permission of the Ethics Commission of the Martin-Luther University considering also the ethical standards laid down in the Helsinki Declaration.

\section{References}

1. Boyle P, Macfarlane GJ, Blot WJ, Chiesa F, Lefebvre JL, Azul AM, De Vries N and Scully C: European School of Oncology Advisory report to the European Commission for the Europe Against Cancer Programme: oral carcinogenesis in Europe. Eur J Cancer B Oral Oncol 31: 75-85, 1995.

2. Haas JF, Rahu M and Staneczek W: Time trends in cancer incidence in the German Democratic Republic 1968-1981. Neoplasma 33: 129-139, 1986.

3. La Vecchia C, Tavani A, Franceschi S, Levi F, Corrao G and Negri E: Epidemiology and prevention of oral cancer. Oral Oncol 33: 302-312, 1997.

4. Bootz F: Reports from the Aachen annual meeting of the German Society for ENT Medicine, Head and Neck Surgery. OncologyEar Surgery. HNO 47: 859-862, 1999.

5. Ambrosch P: Screening studies for early detection of carcinomas of the upper aerodigestive tract. HNO 44: 609-611, 1996.

6. Slaughter DP, Southwick HW and Smejkal W: Field cancerization in oral stratified squamous epithelium; clinical implications of multicentric origin. Cancer 6: 963-968, 1953. 
7. Weinberg RA: How cancer arises. Sci Am 275: 62-70, 1996.

8. Carrano AV and Natarajan AT: International Commission for Protection Against Environmental Mutagens and Carcinogens. ICPEMC publication no. 14. Considerations for population monitoring using cytogenetic techniques. Mutat Res 204: 379-406, 1988.

9. Anders A, Groger H, Anders F, Zechel C, Smith A and Schlatterer B: Discrimination of initiating and promoting carcinogens in fish. Ann Rech Vet 22: 273-294, 1991.

10. Anders A, Zechel C, Schlatterer B, Groger H, Schmidt D, Smith A and Anders F: Genetic and molecular approach for breeding and use of laboratory fish for the detection of agents with carcinogenic and/or promoting activity. Bull Cancer 78: 415-433, 1991.

11. Cohen SM and Ellwein LB: Genetic errors, cell proliferation, and carcinogenesis. Cancer Res 51: 6493-6505, 1991.

12. Renan MJ: How many mutations are required for tumorigenesis? Implications from human cancer data. Mol Carcinog 7: 139-146, 1993.

13. Califano J, van der Riet P, Westra W, Nawroz H, Clayman G, Piantadosi S, Corio R, Lee D, Greenberg B, Koch W and Sidransky D: Genetic progression model for head and neck cancer: implications for field cancerization. Cancer Res 56: 2488-2492, 1996

14. Bradford CR, Zhu S, Poore J, Fisher SG, Beals TF, Thoraval D, Hanash SM, Carey TE and Wolf GT: p53 mutation as a prognostic marker in advanced laryngeal carcinoma. Department of Veterans Affairs Laryngeal Cancer Cooperative Study Group. Arch Otolaryngol Head Neck Surg 123: 605-609, 1997.

15. Masuda M, Hirakawa N, Nakashima T, Kuratomi Y and Komiyama S: Cyclin D1 overexpression in primary hypopharyngeal carcinomas. Cancer 78: 390-395, 1996.

16. Mineta H, Borg A, Dictor M, Wahlberg P and Wennerberg J: Correlation between p53 mutation and cyclin D1 amplification in had and neck squamous cell carcinoma. Oral Oncol 33: 42-46, 1997.

17. Mineta H, Miura K, Takebayashi S, Ueda Y, Misawa K, Harada H, Wennerberg J and Dictor M: Cyclin D1 overexpression correlates with poor prognosis in patients with tongue squamous cell carcinoma. Oral Oncol 36: 194-198, 2000.

18. Cohen SM and Ellwein LB: Cell proliferation in carcinogenesis. Science 249: 1007-1011, 1990.

19. Shin DM, Voravud N, Ro JY, Lee JS, Hong WK and Hittelman WN: Sequential increases in proliferating cell nuclear antigen expression in head and neck tumorigenesis: a potential biomarker. J Natl Cancer Inst 85: 971-978, 1993.

20. Schwartz JL, Gu X, Kittles RA, Baptiste A and Shklar G: Experimental oral carcinoma of the tongue and buccal mucosa: possible biologic markers linked to cancers at two anatomic sites. Oral Oncol 36: 225-235, 2000.

21. Bloching M, Hofmann A, Lautenschlager C, Berghaus A and Grummt T: Exfoliative cytology of normal buccal mucosa to predict the relative risk of cancer in the upper aerodigestive tract using the MN-assay. Oral Oncol 36: 550-555, 2000.
22. Piffko J, Bankfalvi A, Joos U, Ofner D, Krassort M and Schmid KW: Immunophenotypic analysis of normal mucosa and squamous cell carcinoma of the oral cavity. Cancer Detect Prev 23: 45-56, 1999.

23. Liu SC and Klein-Szanto AJ: Markers of proliferation in normal and leukoplakic oral epithelia. Oral Oncol 36: 145-151, 2000.

24. Martinez-Lara I, Gonzalez-Moles MA, Ruiz-Avila I, Bravo M, Ramos MC and Fernandez-Martinez JA: Proliferating cell nuclear antigen (PCNA) as a marker of dysplasia in oral mucosa. Acta Stomatol Belg 93: 29-32, 1996.

25. Zain RB, Sakamoto F, Shrestha P and Mori M: Proliferating cell nuclear antigen (PCNA) expression in oral squamous cell carcinoma - an aid to conventional histological grading? Malays J Pathol 17: 23-30, 1995.

26. Prives C and Hall PA: The p53 pathway. J Pathol 187: 112-126, 1999.

27. Bosch FX, Homann N, Conradt C, Dietz A and Erber R: p53 mutations/p53 protein overexpression. Differential significance for the progression of head-neck carcinomas. HNO 47: 833-848, 1999.

28. Ahomadegbe JC, Barrois M, Fogel S, Le Bihan ML, DoucRasy S, Duvillard P, Armand JP and Riou G: High incidence of p53 alterations (mutation, deletion, overexpression) in head and neck primary tumors and metastases; absence of correlation with clinical outcome. Frequent protein overexpression in normal epithelium and in early non-invasive lesions. Oncogene 10 : 1217-1227, 1995.

29. Ma L, Ronai A, Riede UN and Kohler G: Clinical implication of screening p53 gene mutations in head and neck squamous cell carcinomas. J Cancer Res Clin Oncol 124: 389-396, 1998.

30. Kyomoto R, Kumazawa H, Toda Y, Sakaida N, Okamura A, Iwanaga M, Shintaku M, Yamashita T, Hiai H and Fukumoto M: Cyclin-D1-gene amplification is a more potent prognostic factor than its protein over-expression in human head-and-neck squamous-cell carcinoma. Int J Cancer 74: 576-581, 1997.

31. Bartkova J, Lukas J, Muller H, Strauss M, Gusterson B and Bartek J: Abnormal patterns of D-type cyclin expression and G1 regulation in human head and neck cancer. Cancer Res 55 949-956, 1995.

32. Friedberg EC, Fuchs RP, Goodman MF, Hanaoka F, Hinkle D, Kunkel TA, Lawrence CW, Livneh Z, Nohmi T, Prakash L, Prakash S, Todo T, Walker GC, Wang Z and Woodgate R: The Y-family of DNA polymerases. Mol Cell 8: 7-8, 2001.

33. Lindahl T, Sedgwick B, Sekiguchi M and Nakabeppu Y: Regulation and expression of the adaptive response to alkylating agents. Annu Rev Biochem 57: 133-157, 1988

34. Simic MG: Introduction to mechanisms of DNA damage and repair. Basic Life Sci 38: 1-8, 1986. 